\title{
ENTRE SILÊNCIOS E RUPTURAS: AÇÃO \\ CULTURAL NA BIBLIOTECA DO INSTITUTO \\ FEDERAL DE EDUCAÇÃO, CIÊNCIA E TECNOLOGIA DO MARANHÃO - CAMPUS TIMON
}

\author{
BETWEEN SILENCE AND RUPTURE: CULTURAL \\ ACTION IN THE LIBRARY OF THE FEDERAL INSTITUTE \\ OF EDUCATION, SCIENCE AND TECHNOLOGY OF \\ MARANHÃO - CAMPUS TIMON
}

\author{
Maria Gezilda e Silva Nascimentoa \\ José Robson Maia de Almeidab \\ Maria Cleide Rodrigues Bernardino ${ }^{\circ}$
}

\begin{abstract}
RESUMO
Introdução: as bibliotecas dos Institutos Federais de Educação, Ciência e Tecnologia são caracterizadas como mistas por abarcar condições de biblioteca escolar e universitária. Este estudo aborda a análise de ações culturais desenvolvidas no IFMA Campus Timon. Objetivos: identificar o papel social do bibliotecário no processo de mediação em ações culturais; incentivar a leitura em olhares e formatos diferentes do papel; discutir ações de incentivos a leitura e a produção cultural na biblioteca do IFMA, como forma de diálogo entre o 'silêncio' e as múltiplas ações promovidas pela biblioteca em questão. Metodologia: pesquisa pesquisa-ação, descritiva e com abordagem qualitativa. Resultados: contribuíram para o rompimento da cultura do silêncio na biblioteca, rompendo com os paradigmas tradicionais inerentes a forma de acesso e uso da informação. Conclusões: as ações realizadas conduziram para o acesso à informação e promoção do gosto pela leitura e cultura no IFMA Campus Timon, transformando a biblioteca local em um espaço dinâmico e prazeroso, além de propor aos bibliotecários da instituição, que estes desenvolvam um perfil de agente cultural, capaz de transcender barreiras e criar condições para que a biblioteca realmente atue como um espaço de produção e criação culturais.
\end{abstract}

Descritores: Ação Cultural. Bibliotecas Mistas. Instituto Federal de Educação, Ciência

\footnotetext{
a Bibliotecária/documentalista do Instituto de Educação Ciência e Tecnologia do Estado do Maranhão, Campus Timon. Mestre em Biblioteconomia, pela Universidade Federal do Cariri (UFCA). E-mail: gezildasilva@hotmail.com

${ }^{b}$ Docente do Programa de Pós-Graduação em Biblioteconomia (PPGB) da Universidade Federal do Cariri (UFCA). Doutor em Educação, pela Universidade Federal do Ceará (UFC). E-mail: robson.almeida@ufca.edu.br

c Professora de Biblioteconomia e do Programa de Pós-Graduação em Biblioteconomia (PPGB) da Universidade Federal do Cariri (UFCA). Doutora em Ciência da Informação, pela Universidade de Brasília (UnB). E-mail: cleide.rodrigues@ufca.edu.br
} 
Entre silêncios e rupturas: ação cultural na Biblioteca do Instituto Federal de Educação, Ciência e Tecnologia do Maranhão - Campus Timon

e Tecnologia do Maranhão - Campus Timon. Cultura do Silêncio - Biblioteca.

\section{INTRODUÇÃO}

O estigma da biblioteca como um lugar de silêncio e quase lúgubre, tornando o ambiente pesado e fatigante para a convivência. A pesquisa traz reflexão sobre o tema, uma vez em que se percebe a necessidade de transformação desse espaço em um ambiente dinâmico, leve, aprazível e cativante, envolvendo, atraindo e conscientizando o usuário da sua participação direta na construção de novos conhecimentos.

Dentro dessas possibilidades vê-se a ação cultural como um instrumento de mudanças, acreditando que a construção do sujeito através da cultura é considerada atribuições do bibliotecário. A biblioteca se configura em um espaço democrático, que é construído por meio do fazer coletivo de sua comunidade usuária, sendo sua função primordial transmitir o conhecimento e cultura às novas gerações, de modo que estas possam apropriar-se desse legado e construir novos conhecimentos.

Analisando o cenário atual no que diz respeito a promoção da biblioteca, bem como as formas de exploração e diversificação de produção do conhecimento e também as mudanças que vem passando o fazer bibliotecário, sentiu-se a necessidade de explorar o tema sobre o bibliotecário como agente das transformações que podem ser promovidas por ações culturais, em especial do Instituto Federal do Maranhão, Campus Timon. Pauta-se nos seguintes questionamentos: quais as influências de ações culturais na dinamização da biblioteca como espaço pedagógico e de produção da informação? E quais as implicações do silencio e/ou da ausência de sons para a dinamização da biblioteca como espaço de evolução social e educacional? Em consequência, ao refletir sobre esta problemática, rompe-se com o estereótipo da biblioteca como local inóspito e de silêncio absoluto e a eleva a uma função social como promotora de ações culturais.

Entende-se que a biblioteca influencia, estimula e facilita o acesso à 
informação através de ações culturais e de dinamização de seu espaço, ao mesmo tempo em que promove o gosto pela leitura e pela cultura, transformando-a em um espaço dinâmico e prazeroso. Compreende-se ainda que, a biblioteca tem muitas vozes e que a cultura do silêncio absoluto e perene pode estagnar essas vozes. Ações culturais em bibliotecas pressupõe um bibliotecário atuante, um perfil de agente cultural, capaz de transcender barreiras e criar condições para biblioteca atuar como produtora de conhecimento e cultura.

O presente trabalho alicerça-se nos seguintes objetivos: refletir sobre o papel social do bibliotecário no processo de mediação em ações culturais; e avaliar ações de incentivos a leitura e a produção cultural realizadas na biblioteca do IFMA, como forma de diálogo entre o 'silêncio' e as múltiplas ações promovidas pela biblioteca em questão.

\section{PROCEDIMENTOS METODOLÓGICOS}

A pesquisa é baseada no método lógico da indução a partir de Prodanov e Freitas (2013, p. 28) ao afirmarem que "[...] no raciocínio indutivo, a generalização deriva de observações de casos da realidade concreta". É caracterizada como observacional, pois observa aquilo que acontece buscando compreender e interpretar os significados das coisas.

Quanto aos objetivos é subsidiada pela pesquisa descritiva, pesquisaação, e análise de abordagem qualitativa. A pesquisa-ação se orienta emformas de ações coletivas como forma de resolução de problemas, em que o pesquisador participa ativamente do processo. Para Thiollent (2011, p. 20) a pesquisa-ação é,

É um tipo de pesquisa social com base empírica que é concebida e realizada em estreita associação com uma ação ou com a resolução de um problema coletivo e no qual os pesquisadores e os participantes representativos da situação ou do problema estão envolvidos de modo cooperativo ou participativo.

A análise teve abordagem qualitativa, pois a preocupação central é transformar situações sociais, visto que tem uma relação direta entre a 
subjetividade do sujeito e o mundo real.

A biblioteca do IFMA - Campus Timon, foi o campo onde se desenvolveram ações com o intuito de promover a dinamização da biblioteca, dar vida, e estimular o leitor a usar o espaço de aprendizagem e construção de novos conhecimentos. As ações foram associadas a datas comemorativas ou temas transversais que oportunizassem a reflexão acerca do papel da biblioteca como espaço de cultura e que possa impactar na percepção de sua imagem pela sua comunidade usuária.

Após a realização das ações, como forma de avaliação dos impactos gerados, foram distribuídos questionários aos participantes sujeitos da pesquisa como coleta de dados que possibilitasse uma análise e orientasse a observação e diagnóstico do problema em estudo. Os questionários tiveram questões fechadas permitindo uma maior compreensão da questão da pesquisa.

\section{BIBLIOTECAS MISTAS E A RELAÇÃO COM A CULTURA}

Reafirma-se que a biblioteca é um espaço de construção do conhecimento e essa construção deve existir, em se tratando de uma biblioteca escolar, desde as series iniciais, portanto, é fundamental que esse espaço esteja adaptado e dispondo de recursos que ofereçam possibilidades de acesso à informação.

Considerando o contexto cultural moderno que estamos vivendo, a biblioteca tem a responsabilidade de apresentar um novo papel educacional na sociedade, não podendo ficar isolada ou estagnada. O bibliotecário tem a função de despertar, estimular, orientar e harmonizar essas mudanças desenvolvendo técnicas que proporcione às pessoas que utilizam esse ambiente sua participação na criação de novos conhecimentos culturais como: a liberdade de expressão para opinar, formular e criar (ROSA, 2009).

As bibliotecas dos Institutos Federais (IF) são consideradas mistas por apresentar caraterísticas tanto de biblioteca escolar, como universitária. Sobre isto Mattos e Pinheiro (2006, p. 180) definem a biblioteca mista como,

[...] união da biblioteca escolar e da universitária, tendo como 
público os alunos de educação infantil, ensinos fundamental, médio e superior, docentes e funcionários da instituição. Seu objetivo principal é dar suporte ao que é proposto no projeto político pedagógico da instituição, abrigando acervo, produtos e serviços em um mesmo local, originariamente o da biblioteca escolar ali existente.

Nesse sentido, pode-se afirmar que as bibliotecas dos IFs se configuram como mistas, por apresentar público que vai desde a educação infantil até o ensino superior. Portanto, diante do novo cenário que se apresentam as bibliotecas dos Institutos Federais, pode-se inferir que o papel do bibliotecário também ganha novas atribuições e ele passa a se dar conta de sua responsabilidade social e cultural junto ao grande público.

Isso posto, afirma-se que as bibliotecas incorporam atualmente outros papeis que vão além da guarda de livros e outros documentos e, nessa missão, o bibliotecário também tem a função de promover o gosto pela leitura, conscientizar o usuário do resgate e produção da cultura, de forma agradável, desempenhando um papel ativo de agente de mudanças sociais.

Cultura é inerente à biblioteca. Pensar cultura como criação e produção de linguagem de uma comunidade é considerar a biblioteca como laboratório, pois é através do conhecimento que se constrói todo um legado da humanidade. Faz-se necessário lembrar alguns conceitos sobre cultura, ação e ação cultural para contextualizar o assunto, no que diz respeito à função das bibliotecas como disseminadora, estimuladora e produtora de cultura. Parte-se do pressuposto de que não existe uma única cultura, ou mesmo que esta seja pura ou estanque, mas que as diferentes culturas possam estar imbricadas, atravessadas, umas às outras, de forma a se estabelecer uma relação intercultural entre os diferentes tipos de manifestações culturais e usuários e construir um espaço em que as divergências sejam aproximadas.

O termo cultura é composto de várias acepções, aqui consideraremos cultura como atributos em comum da espécie humana que a distingue dos demais seres vivos, isto é, cultura como característica universal de todos os homens, elemento libertador de toda forma de alienação e opressão.

No que diz respeito à ação cultural, pondera-se ação no sentido literal da 
palavra denotando agir, fazer algo que modifique e cause efeito. Como sinônimo de influência, ação é a capacidade de ocasionar resultados em algo ou alguém. Dentro dessas possibilidades a ação é um instrumento de mudanças. Na visão de Coelho Netto (2001, p. 12):

Ação é um conceito cujo sentido fica mais claro quando confrontado com outro, "fabricação", de amplo trânsito não explicitado e não confessado. A fabricação é um processo com um início determinado, um fim previsto e etapas estipuladas que devem levar ao fim preestabelecido. A ação, de seu lado, é um processo com início claro e armado, mas sem fim especificado e, portanto, sem etapas ou estações intermediárias pelas quais se deva necessariamente passar - já que não há um ponto terminal ao qual se pretenda ou espere chegar.

Compreende-se que quando a ação proposta é confrontada em sua estrutura cultural temos como resultantes o despertar cognitivo nos processos de questionar, elaborar, evidenciar, produzir novos significados que gerarão novas ações comportamentais.

Coelho Netto (2001, p. 8) define ação cultural como o: "[...] desejo de fazer da arte e da cultura instrumento deliberados de mudança do homem e do mundo, de forma a possibilitar mais interações entre o homem e a sociedade.

Percebe-se, por meio destes pensamentos, citando Bazílio (2014, p. 22) "[...] que as questões principais no processo de ação cultural consistem na criação, transformação, conscientização e a libertação dos indivíduos". Portanto, entende-se que o papel social do bibliotecário se inicia a partir do momento que ele tornar efetivo o dever de propiciar aos seus usuários múltiplas formas para o seu crescimento enquanto pessoas de direitos e deveres, e assim, vir a ser sujeitos críticos perante a sociedade em que vive.

\subsection{AÇÃo CULTURAL COMO PROCESSO EDUCATIVO: O BIBLIOTECÁRIO MEDIADOR}

O ato de aprender está ligado ao processo de escolarização e seus aspectos teóricos e práticos para isso é importante a troca de informações dos conhecimentos acumulados.

A ação cultural como processo educativo envolve o bibliotecário como condutor do ato, tornando o público independente. Ação cultural pressupõe uma 
noção de cultura como processo contínuo de aprendizado. Em bibliotecas o desenvolvimento de ações culturais deve promover o lúdico e oportunizar a reflexão e o conhecimento. $O$ desenvolvimento de ações culturais em bibliotecas, sobretudo, em bibliotecas como as escolares ou mistas como as dos IFs, é cumprir o papel social promovendo a integração entre cultura, conhecimento e leitor.

Cavalcanti, Araújo e Duarte (2015, p. 21) afirmam que a biblioteca "[...] necessita adaptar-se a essa nova realidade social, revestindo-se de um caráter transformador tendo como mediador o bibliotecário para criar e desenvolver mecanismos que facilitem a interação entre o usuário e a biblioteca, proporcionando assim novos conhecimentos".

Pode-se perceber conforme afirma Cabral (1999) que o trabalho de ação cultural desenvolvido pelo bibliotecário exige um profissional com perfil diferenciado e um tipo de formação que seja interdisciplinar. Corroborando com o pensamento de Vicentini et al. (2007, p. 2) de que "[...] uma biblioteca deve servir a diferentes interesses e classes sociais e ser um espaço onde se acumulam contradições, oposições, afirmações, negações, tradições e inovações", e que, portanto, o bibliotecário deve ser o profissional que atuará neste espaço de forma competente e dinâmica.

\subsection{A BIBLIOTECAS E O SILÊNCIO ABORDAGENS SOBRE CONCEITOS E ESTEREÓtIPOS}

O legado cultural da biblioteca como espaço entre limitação e liberdade, no qual a instauração do silêncio era uma imposição inicialmente prevista em seus regulamentos. Para entender essa relação entre passado, presente e futuro é necessário fazer um retrospecto sobre a história das bibliotecas. É difícil se dissociar a história da humanidade da história das bibliotecas e do conhecimento. Do papiro a tela do computador, as transformações ocorridas ao longo dos séculos, são correlatas com a evolução humana. Até porque, é impossível haver a evolução sem evoluírem também suas exigências e necessidades dentro das bibliotecas, tendo em vistas se apropriarem mudanças 
para que este espaço possa se modificar, evoluir e adequar-se às novas demandas.

$\mathrm{Na}$ história do homem, as revoluções vividas impactaram substancialmente nas transformações das bibliotecas haja vista as revoluções tecnológicas, principalmente a dos computadores, que foram beneficiadas no processo de controle, na produção de registro, bem como no aparecimento de novos suportes para o acervo e na preservação das suas informações.

Percebe-se, portanto, que as transformações sociais, culturais, econômicas, científicas e tecnológicas, vêm impondo mudanças significativas no modo de atuação das bibliotecas.

Fonseca (2007, p. 50) propõe um novo conceito de biblioteca, "[...] coleção e outros documentos, devidamente classificados e catalogados". Por outro lado, Silva (2017), traz novos olhares e conceitos contemporâneos, refletindo a biblioteca numa era pós-custodial, onde a informação tem significado e ação.

A luz desse conceito, a biblioteca deve ser considerada como um espaço polivalente. Entende-se aqui por polivalente, aquele espaço que apresenta múltiplos valores e que oferece várias possibilidades, que envolve vários campos de atividades. Nessa perspectiva, a biblioteca funcionaria como aparelhos culturais que realmente possibilitam a democratização da informação, bem como propicia as condições necessárias para o fomento à leitura e a construção do conhecimento.

No conceito de Fonseca (2007) percebe-se nitidamente que a formação das bibliotecas aconteceu num cenário onde saber e poder tinham trajetória paralela, reis e outras personalidades de destaque formavam suas coleções, assim também como os mosteiros que copiavam e produziam seus próprios livros.

Com o passar dos séculos e as mudanças culturais, novas técnicas de leitura desenvolveram-se, especialmente, a partir das revoluções de Gutenberg e da revolução Tecnológica, sendo que a última não modificou. Nesse sentido observa-se que é percebível a exigência de total ausência de sons nos ambientes de informação, 


\begin{abstract}
À liberdade de que o espaço necessita é preterida pela continuidade do silêncio historicamente enraizado em sua constituição, na manutenção do espaço sagrado, complicador forte para que ocorram atividades lúdicas e que exista interação (BASTOS; PACÍFICO; ROMÃO, 2011, p. 627).
\end{abstract}

Mesmo com todos os avanços tecnológicos e evolução teórico conceitual de biblioteca, ainda persiste na maioria dos casos uma biblioteca silenciosa e hostil, um ambiente que mais afasta do que cativa. O leitor que não se submete as regras, é visto como transgressor, oposto a tudo isso, novos estudiosos da área defendem a ideia de um espaço dinâmico e criativo, pois as revoluções acontecidas proporcionaram uma evolução na forma de ler, escrever e produzir conhecimento, bem como igualmente levaram a repensar o uso do espaço das bibliotecas, como ambientes multiculturais, onde conhecimento, cultura, prestação de serviços, possam ser oferecidos de forma eficaz e democrática ao mais diversificado público.

\title{
4 DESCRIÇÃO DAS ATIVIDADES CULTURAIS DESENVOLVIDAS NA BIBLIOTECA
}

A primeira ação foi nomeada como "Foliões do Conhecimento" e realizada no dia 28 de fevereiro de 2018, das 17:00 às 18:00. A apresentação foi em forma de marchinha, com o objetivo de discutir a influência da cultura africana no carnaval de rua brasileiro. Também foi realizada uma conscientização sobre o carnaval sem assédio.

O cenário da ação, foi o espaço físico da biblioteca, devidamente ornamentado e ambientado, com temas carnavalescos, adornados com máscaras, serpentinas, chapéus, pinturas e exposições de fotos dos carnavais antigos, dispostos em cavaletes. Durante a ação, a banda de música do Campus animou o público do turno vespertino, formado por alunos do ensino médio.

Entre os destaques da ação, um dos alunos, participou como protagonista do evento, fazendo uma apresentação sobre a história do carnaval e suas evoluções com o passar dos anos até os dias atuais. Despertar na comunidade o desejo de aprender sobre um determinado tema, mostrar sua cultura e produzir 
algum tipo de conhecimento foi a proposta da ação realizada.

Esta ação encontra apoio no pensamento de Santos (2015, p. 179),

[...] ação cultural, na maioria das vezes, inclui uma animação cultural, até como veículo de divulgação. Mas a ação cultural não se limita a mostrar os bens culturais, ela possibilita a participação das pessoas na produção destes bens, facilitando a aglomeração de indivíduos e grupos que se apropriam dos espaços e equipamentos da biblioteca. Assim, o que ela faz é tentar criar oportunidades para que o mero usuário, o espectador, possa também elaborar sua produção.

Pode-se perceber nesta ação a influência das ações culturais na dinamização e ainda a produção de conhecimento, foi exatamente o que aconteceu quando um dos alunos, participou como um dos protagonistas do evento, fazendo uma apresentação sobre a história do carnaval e suas evoluções com o passar dos anos até os dias atuais.

Como feedback do impacto causado pelo cenário e atração, avaliou-se aspectos qualitativos, presentes, por parte dos alunos, nos olhares de surpresa e nos comentários entusiasmados, como: "meu Deus!!! nunca vi essa biblioteca tão bonita"; "Aqui hoje pode-se dançar"; "Hoje é dia de folia nessa biblioteca".

Outra repercussão visível analisada foi o envolvimento e participação dos outros servidores do IF, ao ouvirem a banda tocar, os quais saíram de suas salas para prestigiar o evento, pontuando com isso a participação de um grande público entre alunos e servidores.

Concluiu-se na avaliação da ação, que bibliotecário como articulador dessa atividade de interação, ensino e aprendizagem, contribuiu no sentido de esclarecer sobre como o espaço da biblioteca pode ser dinâmico e promover cultura, dependendo do horário e programação planejados e pré-estabelecidos. Percebe-se que é possível adequar um espaço de silêncio a uma atividade sonora sem prejuízos a sua funcionalidade e ainda promover cultura, debate e informação.

O fator motivador da segunda ação, deu-se em razão do dia do Índio. Como contribuição cultural, teve-se o embasamento da cultura indígena, culminando na realização de uma oficina de bordado artesanal. A oficina ganhou o nome de "Bordando a cultura indígena", sendo realizada no dia 26 de abril de 
2018, das 19:00 as 22:00, também no espaço físico da biblioteca. A ação contou com o público do EJA, principal público alvo da oficina. O motivo da escolha desse público, foi o de oferecer uma capacitação, que pudesse agregar possibilidades de renda, considerando que o perfil desses alunos, são de pessoas produtivas e necessitadas socioeconomicamente, frente a um mercado de trabalho competitivo e exigente.

A proposta de trazer informação em forma de minicurso de bordado foi a de proporcionar possibilidades de acrescentar a renda e ainda a oportunidade de aprender uma atividade que sirva como relaxamento e lazer como foi a fala de alguns durante a ação.

A reação dos alunos foi de total surpresa, ao perceber o espaço bibliotecário sendo utilizado de outra forma, com outras possibilidades de aprendizagem. Através de avaliação qualitativa da ação, percebeu-se como retorno, reação positiva dos alunos, aonde foram ouvidos, vários comentários entusiasmados do tipo: "nossa!!! Como bordar é relaxante"; "eu já consegui tantas coisas difíceis, porque que eu não vou conseguir bordar?".

Entre os destaques dos alunos na oficina realizada, teve-se a desenvoltura de um jovem e um senhor, que surpreendeu a todos presentes pela habilidade no manuseio com a agulha, mesmo nunca tendo vivenciado tal experiência. Como recompensa e incentivo ao ensino aprendizagem pelo esforço e participação dos alunos na oficina, todos poderiam levar consigo o próprio bordado realizado, bem como os materiais utilizados na atividade.

Essas ações evidenciam, que, dentro do sistema cultural contemporâneo, torna-se imprescindível uma política cultural para bibliotecas que visem o trabalho com a cultura, visando o desenvolvimento social. Notamos como o público do IFMA, Campus Timon, necessita e responde bem a este tipo de iniciativo proposto por sua biblioteca.

Buscando aproximar a comunidade do seu acervo físico e cultural, através de formas dinâmicas e criativas, entende-se que a biblioteca do IFMA está buscando se comportar como fomentadora de ações culturais na sua comunidade acadêmica e que, através de diferentes atividades, promove a não 
somente a leitura, mas também desenvolvimento intelectual e social saudável da comunidade que atende.

Ação cultural como um processo educativo pode ser proposto nos infinitos temas que permeiam o método de escolarização. Atentando-se a necessidade do contexto em que se insere a biblioteca do IFMA - Timon, que tem como público alvo adolescentes e jovens secundaristas, percebeu-se a necessidade de abordar temas relacionados a sexualidade, que ainda é um assunto tabu no meio familiar e pouco abordado nas escolas.

Foi proposto para essa ação um estilo bate papo sobre o projeto da professora Lessandra Ribeiro que promove informações relevantes para saúde e bem-estar dos participantes. Ainda pelas comemorações ao dia Internacional da mulher, no dia 12 de março foi apresentado durante uma conversa descontraída o projeto: 'na adolescência, não faça filhos, leia livros'.

$\mathrm{Na}$ oportunidade de abertura do evento foi colocado a importância da conscientização de uso do espaço biblioteca, demonstrando que aquela ação tinha a intenção de revelar um espaço dinâmico e multicultural. E que o projeto reportava exatamente incentivos a leitura e a produção cultural na biblioteca do IFMA, como forma de diálogo entre o "silêncio" e as múltiplas ações promovidas pela biblioteca em questão. Como asseveram Bernardino e Suaiden (2011, p. 32):

\begin{abstract}
A biblioteca como lugar de interação entre a leitura e o leitor, conservação e preservação da memória, mas, sobretudo, uma interseção entre esta e seus leitores e principalmente para estes, sejam dedicados todos os seus esforços, tanto no que diz respeito à organização e tratamento da informação como à disseminação da cultura. Uma biblioteca que atue como centro fomentador e gerador do conhecimento [...].
\end{abstract}

Ao pensar no usuário como a parte primordial do trabalho e existência da biblioteca, percebe-se que sua função como transformadora da sociedade e ciente seu papel social é mais evidente.

A professora Lessadra Ribeiro discorreu de forma elucidativa e sem 'tabus' sobre temas ligados a sexualidade, como os riscos do sexo precoce e sem segurança, as consequências sociais e os riscos físicos de uma gravidez 
precoce, as DSTs, e a importância da leitura para a vida pessoal e profissional. Os alunos interagiram com perguntas e exemplos, momentos que foram de total descontração.

No final do bate papo que durou cerca de 1 hora e meia, era visível a empolgação dos alunos e a conscientização em relação aos temas abordados, percebeu-se então que foi cumprido o papel de democratização da informação no espaço, tornando os usuários informados, consciente de suas responsabilidades.

Um espaço com as características descrita acima é o que se idealiza ao propor ações para a sua dinamização, mesmo sabendo dos enfrentamentos à resistências e quebra de paradigmas. A atividade foi pensada na perspectiva da ação cultural como processo educativo com referência na educação inclusiva. Nesse processo as bibliotecas têm um papel inclusivo contribuindo para as práticas pedagógicas.

Atenta a essas necessidades a biblioteca do Campus Timon já dispõe de acervo em Braille, piso tátil, computador com cabine rebaixada e ainda software específicos instalados nos computadores para auxiliar os alunos com baixa visão.

Considerando todos esses aspectos e considerando ainda o mês de abril como referência no tema inclusão foi que pensamos a atividade desenvolvida dia 05 de abril de 2019 com o seguinte tema. Roda de conversa: 'conversando e sinalizando a libras', com o Professor Estélio Barbosa. A importância também se deu pelo domínio que o docente tem na área com quatro livros publicados.

$A$ atividade envolveu alunos do ensino médio e superior, considerando que a necessidade de comunicação em libras é de todos. A interação foi notória, muito empolgados, atentos e dispostos a repetir cada comando foi que se observou na oficina desenvolvida dentro da roda de conversa com o professor.

A construção do processo de inclusão é fato recente na sociedade, porém faz se necessário à disposição na interação dessa composição. As bibliotecas como partícipes desse processo têm se voltado para as amplas possibilidades de como: acervos, tecnologias assistivas, aparelhamento das estruturas. 
Nessa perspectiva foi que propomos incentivar a leitura em olhares e formatos diferentes do papel, a libras como língua oficial foi escolhida em forma de ação cultural como meio de promover a inclusão social, sendo este também um dos papéis sociais da biblioteca, promovendo a cidadania. Esta ação evidenciou que o Brasil é um país bilíngue, pois a Língua Brasileira de Sinais (Libras) foi reconhecida como a segunda língua oficial do Brasil pela Lei $n^{\circ}$ 10.436, de 24 de abril de 2002.

Envolver a comunidade acadêmica no ato de inclusão é dever da biblioteca quando esta se encontra inserida num ambiente que desempenha um papel democratizado como agente de transformação. É um direito garantido ao aluno de acesso à informação e aos espaços que promovem esse conhecimento.

Percebe se nesse contexto a necessidade de capacitação dos profissionais que estão à disposição nesses espaços.

\section{RESULTADOS E ANÁLISES}

A análise deu-se a partir das observações feitas, conciliando a prática bibliotecária e as necessidades dos usuários no ambiente em que foi feita a pesquisa, considerando que nas Ciências Sociais o homem é o sujeito e objeto da pesquisa e faz se necessário a compreensão dos processos sociais para interpretação dos fatos.

Para tanto, foram desenvolvidas ações com a finalidade de trazer o público da biblioteca para observamos quais as suas necessidades e desejos a serem realmente atendidos. Com esse escopo foi utilizado questionário fechados estruturado que foi distribuído ao público participante sendo lhes facultado o tempo de 30 dias para devolução. As observações por parte do pesquisador eram feitas no ato da ação onde era possível perceber a receptividade dos participantes em relação as atividades desenvolvidas.

Ao final do tempo estipulado foram recolhidos todos os questionários e feito uma numeração para facilitação da análise, ao todo o banco de dados foi formado por 81 indivíduos e por 13 variáveis, sendo 3 variáveis de 
caracterização, 9 variáveis sobre ações culturais e 1 variável referente aos grupos.

$\mathrm{Na}$ análise descritiva das variáveis foram usadas as frequências absolutas e relativas. Para comparar a relação entre as variáveis de caracterização e as ações culturais foi utilizado o teste de Qui-quadrado (AGRESTI, 2002) e o teste Exato de Fisher (AGRESTI, 2002).

Corroborando com a informação já exposta antes, a maioria $(76,54 \%)$ dos participantes são menores de 18 anos e alunos ingressantes no Ensino Médio $(65,43 \%)$, o que demanda uma necessidade maior de conquista e fidelização desse público, pois são na essência muito dispersos e voltados para as tecnologias, conclusão a partir das observações do pesquisador. Nesse aspecto as atividades mais lúdicas e espontânea foram mais envolventes. Contamos apenas com $(4,94 \%)$ dos participantes com Bacharelado/Licenciatura e somente $(1,23 \%)$ com Mestrado/Doutorado.

Esse público faz uso da biblioteca com a finalidade de pesquisa, essa questão foi observada quando a participação deles se deu na oficina de libras, o que configura a busca pela capacitação e aprendizado. A participação feminina foi um pouco mais intensa com (53,09\%), porém consideramos um público bem equilibrado quanto ao gênero.

A maioria dos respondentes $(81,48 \%)$ assistiu ou participou de alguma ação cultural na biblioteca do IFMA Campus Timon. Porém (12,35\%) disseram 'Não' ter participado e $(6,17 \%)$ disseram 'Não Lembrar', esses números define que uma parcela significativa dos questionados, mesmo tendo sido explicado antes de cada ação, não sabem ou não entenderam o que seja uma ação cultural.

Considerando o porquê da participação nas atividades, a 'Curiosidade' teve um impacto com $(43,94 \%)$ o que confirma a necessidade de algo novo, criativo que chame atenção da comunidade acadêmica para o espaço biblioteca. Porém indicadores mostram que $(25,76 \%)$ respondeu que por obrigatoriedade participou das ações. Isso se determina pela característica das ações planejadas, os professores que viam similaridade dos temas abordados e suas 
disciplinas liberavam os alunos para participação. O quantitativo que participou pelo 'Conhecimento ou Falta de Conhecimento do Tema', foi um resultado satisfatório $(22,73 \%)$ o que sugere a necessidade de aprendizado e remete a biblioteca como um local de produção de conhecimento.

Quanto o grau de importância da ação cultural na biblioteca o índice 'Excelente' somou (38,27\%), seguido pelo 'Bom' com (32,10\%) e ainda 'Ótimo' com $(25,93 \%)$ sugere que foi bem aceito pelo público e que as ações são necessárias para a dinamização do espaço. Essa afirmação se confirma quando $(70,37 \%)$ dos participantes da pesquisa acreditaram que essas ações culturais incentivam a buscar novas informações sobre as temáticas abordadas.

Quando o questionamento foi a importância de ações que envolvam a leitura em diferentes suportes diferentes do livro impresso, um pouco mais da metade (50,62\%) entendeu que 'Sim', 'Muito Importante', outros olhares e formas de apreender, conhecer e construir conhecimento.

O velo ao silêncio já não tão legitimado pelo nosso público, contrariando o que ainda ocorre na maioria das bibliotecas, (65,43\%) acreditam ser uma 'Excelente Ideia' romper com a cultura do silencio nas bibliotecas, seguido ainda por uma expressiva maioria $(30,86 \%)$ que acham 'Boa Ideia' a ruptura.

O bibliotecário desenvolveu um importante papel na visão dos participantes onde $(53,09 \%)$ julgaram como 'Importante' a participação do bibliotecário como mediador nessas ações. E para (41,98\%) esse profissional é designado como 'Muito Importante'.

As atividades desenvolvidas já mostram seus efeitos quando (35,80\%) dos participantes responderam que depois da participação da ação foram incentivados a realizar 'Algumas' produções cultural, artesanal e/ou intelectual sobre o tema em seu ambiente de estudo ou trabalho, na contramão vemos, porém, que quase a mesma porcentagem $(34,57 \%)$ não desenvolveu 'Nenhuma' produção o que mostra a apatia ou falta de vontade em criar ou produzir ao diferente.

Diante das inquietações na busca pela compreensão de quais as influências das ações culturais na dinamização da biblioteca, percebeu-se a 
importância quando a maioria dos participantes $(38,27 \%)$ classificou como excelente o grau de importância dessas ações. Observou-se também nos comentários dos participantes, da empolgação e surpresa que receberam as atividades, nas falas inusitadas como: "nunca tinha visto essa biblioteca tão animada" e ainda "essas atividades têm que acontecer mais vezes". A atenção e interação na participação autêntica a necessidade de uso desse espaço de forma multicultural.

As implicações do silencio e/ou ausência de sons para a dinamização da biblioteca entusiasmou o público, que percebeu ser possível usar o espaço da biblioteca de forma responsável e com outros objetivos que não seja somente o estudo silencioso e o empréstimo de livros. Esses resultados foram confirmados quando a maioria absoluta $(65,43 \%)$ respondeu que foi uma excelente ideia romper com a cultura do silencio para realização da atividade.

\section{CONSIDERAÇÕES FINAIS}

Ao finalizar este trabalho, não se traz respostas para todas as interrogações, mas, uma reflexão. Percebe-se ao escutar/observar e conversar com cada participante da pesquisa, as conexões entre o ser e o fazer que agregam o bibliotecário.

As ações culturais desenvolvidas influenciam diretamente na dinamização do espaço, podemos constatar tal fato quando a maioria considerou relevante a ação cultural na biblioteca. A aceitação e disposição do público em participar do estudo ficou fulgente durante as observações e ainda nas falas dos presentes quando diziam: "tem que acontecer mais vezes", "nunca pensei de ver essa biblioteca tão animada".

Pondera-se ainda sobre quais as implicações do silêncio e/ou da ausência de sons para a dinamização da biblioteca como espaço de evolução social e educacional? Surpreendeu a afirmação da maioria sobre a ideia da ruptura do silêncio para realização da atividade como excelente. Nota-se o anseio do público em ver uma biblioteca ativa, "viva", movimentada, um espaço onde o velo 
ao silêncio não seja a prática mais importante, percebemos a necessidade de desconstrução dessa imagem, considerando que a biblioteca não pode ser entendida somente um "deposito de livros" os seus usuários não podem ser amainados apenas como leitores. A razão de ser da biblioteca são os usuários, partindo dessa premissa a sua demanda vai além da leitura no suporte impresso, passa pela construção de ideias, consequentemente, produção de novos conhecimentos.

Nesta perspectiva considera-se que os objetivos foram atingidos, além de despertar na equipe de servidores da biblioteca da instituição um perfil de agente cultural, capaz de transcender barreiras e criar condições para que a biblioteca realmente atue como um espaço de produção e criação culturais. Foi exatamente o que se observou durante a realização das ações, o público teve acesso a informações de forma lúdica, divertida, descontraída despertando a curiosidade pelos temas abordados e ainda o desejo por mais mediações como as que aconteceram.

O papel social do bibliotecário no ato de mediação em ações culturais pode ser compreendido como sujeito ativo na construção do processo, usando de todos os meios para viabilizar as práticas, sem imposição, mas interagindo e persuadindo a comunidade de que o usuário é a razão elementar de existência da biblioteca, além do perfil de caráter educativo o bibliotecário deve possuir características politizadas, considerando que o processo de mediação cultural é revestido de atitudes transformadoras e os participantes da ação devem ser estimulados a consumir, absorver e reelaborar conhecimento.

A realização das ações de incentivos a leitura e a produção cultural na biblioteca do IFMA, como forma de diálogo entre o 'silêncio' e as múltiplas ações promovidas pela biblioteca em questão contribuiu para a conscientização de que não há uma total ausência de sons, portanto nunca chegaremos a um status de silêncio absoluto no espaço da biblioteca, mas que é possível usar o espaço, para as mais diversas atividades em momentos programados, entendemos a necessidade do silêncio, mas compreendemos também durante as nossas observações que a imposição absoluta ao silêncio na biblioteca atrapalha a 
aproximação do aluno com ambiente de informação.

Conclui-se que é preciso definir um novo conceito para biblioteca diante das transformações sofridas e nesse novo cenário. As atribuições são de um espaço não apenas de conservação e guarda de livros, porém de construção, produção e disseminação do conhecimento e sobrepondo o sujeito leitor um ser social, discursivo, marcado por conflito, seria incoerente cobrar desse cliente um comportamento com características do mundo medieval nesse contexto faz se necessário romper com os paradigmas tradicionais da forma de uso do espaço biblioteca.

\section{REFERÊNCIAS}

AGRESTI, Alan. Categorical analysis. New York: John Wiley, 2002.

BASTOS, Gustavo Grandini; PACÍFICO, Soraya Maria Romano; ROMÃO, Lucília Maria Sousa. Biblioteca escolar: espaço de silêncio e interdição. Liinc em Revista, Rio de Janeiro, v. 7, n. 2, p. 621-637, 2011.

BAZÍLIO, Ana Paula Matos. Mediação, leitura e inclusão social: um caminho para ação cultural na biblioteca pública- o caso das bibliotecas parques. NiteróiRj, 2014. Dissertação (Mestrado em Ciência da Informação) - Instituto de arte e comunicação social, Universidade Federal Fluminense, Niterói, 2014.

BERNARDINO, Maria Cleide Rodrigues; SUAIDEN, Emir Jose. O papel social da biblioteca pública na interação entre informação e conhecimento no contexto da ciência da informação. Perspectivas em Ciência da Informação, Belo Horizonte, v. 16, n. 4, p. 29-41, set. 2011. Disponível em: http://portaldeperiodicos.eci.ufmg.br/index.php/pci/article/view/1257. Acesso em: 10 jun. 2019.

CABRAL, Ana Maria Rezende. Ação cultural: possibilidades de atuação do bibliotecário. In: VIANNA, Márcia Milton; CAMPELLO, Bernadete; MOURA, Victor Hugo Vieira. Biblioteca escolar: espaço de ação pedagógica. Belo Horizonte: EB/UFMG, 1999. p. 39-45.

CAVALCANTI, Ivanilda Bezerra; ARAÚJO, Claudialyne Silva; DUARTE, Emeide Nóbrega. O bibliotecário e as ações culturais: um campo de atuação.

Biblionline, v. 11, n. 1, p. 21-34, 2015. Disponível em: http://periodicos.ufpb.br/ojs2/index.php/biblio/article/view/16626. Acesso em: 15 jul. 2018. 
COELHO NETTO, José Teixeira. O que é ação cultural. São Paulo: Brasiliense, 2001.

FONSECA, Edson Nery. Introdução à biblioteconomia. 2. ed. Brasília: Briquet de Lemos, 2007.

MATTOS, Ana Luiza de Oliveira; PINHEIRO, Michelle. O perfil das novas bibliotecas escolares-universitárias (bibliotecas mistas) nas instituições de ensino privado no Estado de Santa Catarina. Revista ACB: Biblioteconomia em Santa Catarina, Florianópolis, v. 11, n. 1, p. 171-184, jan./jul., 2006. Disponível em: https://revista.acbsc.org.br/racb/article/view/474/602. Acesso em: 15 jul. 2018.

PRODANOV, Cleber Cristiano; FREITAS, Ernani César de. Metodologia do trabalho científico: método e técnicas da pesquisa e do trabalho acadêmico. 2. ed. Novo Hamburgo: Feevale, 2013.

ROSA, Anelise Silva Jesus da. A prática da ação cultural em bibliotecas.

Revista ACB: Biblioteconomia em Santa Catarina, Florianópolis, v. 14, n. 2, p. 372-381, jul./dez. 2009. Disponível em:

https://revista.acbsc.org.br/racb/article/view/675. Acesso em: 27 out. 2016.

SANTOS, Josiel Machado. Ação Cultural em Bibliotecas Públicas: o bibliotecário como agente transformador. Revista Brasileira de

Biblioteconomia e Documentação. São Paulo, v. 11, n. 2, p. 173-189, jun./dez. 2015.

SILVA, Jonathas Luiz Carvalho. Afinal, o que é uma biblioteca? Biblioo cultura informacional. Artigo. 24 ago. 2017.

Disponível em: https://biblioo.cartacapital.com.br/afinal-o-que-e-umabiblioteca/ Acesso em: 18 jun. 2019.

THIOLLENT, Michel. Metodologia da pesquisa-Ação. 18. ed. São Paulo: Cortez, 2011.

VICENTINI, Luis Atílio., MARTINS, Valéria dos Santos Gouveia; RODRIGUES, Célia A., ALVES, Aparecido D., FERREIRA, Danielle T., TRUZZI, Marilda. O papel da biblioteca universitária no incentivo à leitura e promoção da cidadania. Biblos, v. 8, n. 27, jan./mar. 2007. Disponível em:

https://dialnet.unirioja.es/servlet/articulo?codigo=2281822. Acesso em: 10 ago. 2018.

\section{BETWEEN SILENCE AND RUPTURE: CULTURAL ACTION IN THE LIBRARY OF THE FEDERAL INSTITUTE OF EDUCATION, SCIENCE AND TECHNOLOGY OF}




\title{
MARANHÃO - CAMPUS TIMON
}

\begin{abstract}
Introduction: The libraries of the Federal Institutes of Education, Science and Technology are characterized as mixed because they embrace school and university library conditions. This study deals with the analysis of cultural actions developed in IFMA - Campus Timon. Objective: to identify the social role of the librarian in the process of mediation in cultural actions; encourage reading in different looks and paper formats; discuss reading incentive actions and cultural production in the IFMA library as a form of dialogue between the "silence" and the multiple actions promoted by the library in question. Methodology: research action research, descriptive and with qualitative approach. Results: they contributed to the rupture of the culture of silence in the library, breaking with the traditional paradigms inherent in the form of access and use of information. Conclusions: the actions carried out have led to access to information and promotion of the taste for reading and culture in the IFMA Campus Timon, transforming the local library into a dynamic and pleasant space, and to propose to the librarians of the institution that they develop an agent profile cultural, capable of transcending barriers and creating conditions for the library to really act as a space for cultural production and creation.
\end{abstract}

Descriptors: Cultural Action. Mixed libraries. Federal Institute of Education, Science and Technology of Maranhão - Timon Campus. Culture of Silence - Library.

\section{ENTRE EL SILENCIO Y LA RUPTURA: ACCIÓN CULTURAL EN LA BIBLIOTECA DEL INSTITUTO FEDERAL DE EDUCACIÓN, CIENCIA Y TECNOLOGÍA DE MARANHÃO - CAMPUS TIMON}

\begin{abstract}
RESUMEN
Introducción: Las bibliotecas de los Institutos Federales de Educación, Ciencia y Tecnología se caracterizan como mixtas porque abarcan las condiciones de las bibliotecas escolares y universitarias. Este estudio trata sobre el análisis de acciones culturales desarrolladas en IFMA - Campus Timon. Objetivo: identificar el rol social del bibliotecario en el proceso de mediación en acciones culturales; Fomentar la lectura en diferentes looks y formatos de papel; Discuta las acciones de incentivo de lectura y la producción cultural en la biblioteca de IFMA como una forma de diálogo entre el "silencio" y las múltiples acciones promovidas por la biblioteca en cuestión. Metodología: investigación, investigación, investigación, descriptiva y con enfoque cualitativo. Resultados: contribuyeron a la ruptura de la cultura del silencio en la biblioteca, rompiendo con los paradigmas tradicionales inherentes a la forma de acceso y uso de la información. Conclusiones: las acciones llevadas a cabo permitieron acceder a la información y promover el gusto por la lectura y la cultura en el Campus Timon de IFMA, transformando la biblioteca local en un espacio dinámico y agradable, y proponer a los bibliotecarios de la institución que desarrollen un perfil de agente.
\end{abstract}


Maria Gezilda e Silva Nascimento, José Robson Maia de Almeida, Maria Cleide Rodrigues Bernardino

Entre silêncios e rupturas: ação cultural na Biblioteca do Instituto Federal de Educação, Ciência e Tecnologia do Maranhão - Campus Timon

Cultural, capaz de trascender barreras y crear condiciones para que la biblioteca realmente actúe como un espacio para la producción y creación cultural.

Descriptores: Acción cultural. Bibliotecas mixtas. Instituto Federal de Educación, Ciencia y Tecnología de Maranhão - Campus Timon. Cultura del silencio - Biblioteca.

Recebido em: 10.07.2019

Aceito em: 09.09.2019 